\title{
Child-Friendly Humanitarian Logistics in Natural Disasters: A Letter to the Editor
}

\author{
Hamed Seddighi (iD ${ }^{1,}{ }^{*}$, Homeira Sajjadi ${ }^{2}$ and Ibrahim Salmani (iD) ${ }^{3}$ \\ ${ }^{1}$ Student Research Committee, University of Social Welfare and Rehabilitation Sciences, Tehran, Iran \\ ${ }^{2}$ Department of Social Welfare Management, University of Social Welfare and Rehabilitation Sciences, Tehran, Iran \\ ${ }^{3}$ Department of Health in Disaster and Emergency, School of Public Health, Shahid Sadoughi University of Medical Sciences, Yazd, Iran \\ "Corresponding author: Student Research Committee, University of Social Welfare and Rehabilitation Sciences, Tehran, Iran. Tel: +98-9133505088, Email: hseddighi@gmail.com
}

Received 2019 June 13; Accepted 2019 July 28.

Keywords: Children, Humanitarian Logistics, Natural Disasters

\section{Dear Editor,}

Natural disasters affect children's health enormously with various examples studied globally (1). It is defined as "A serious disruption of the functioning of a community or a society, leading to one or more of the following: human, material, economic and environmental losses, and impacts" (1). This definition includes natural disasters and humanitarian emergencies.

Children include anyone under the age of 18 years based on the United Nations' Convention on the rights of children (1). Children are the most vulnerable group in disasters. In the developing countries where children have a major share of the population, the number of fatalities from natural disasters is more than developed countries (2), that could be due to the limited supporting systems. Climate change has increased natural disasters in the world, and every year, 400 disasters occur globally (2). A quarter of the child population in the world means that more than 500 million children are living in disasteraffected areas. Some of these children are separated or unaccompanied (1). In such harsh conditions, providing vital needs like food, water, medical care, and shelter becomes uncertain. Thus, during disasters, many children are in critical need for humanitarian aid for themselves and their family.

Humanitarian logistics aims at helping people affected by disasters to survive (3). Thus, it is essential to provide a reliable system for humanitarian logistics at different phases of a disaster (Preparedness, immediate response, reconstruction) (3). A major outcome of humanitarian logistics is alleviating the suffering of affected people especially vulnerable groups from planning to distributing goods and materials from the point of origin (such as donors and producers) to the point of consumption (af- fected people) (3). Many actors have a role in humanitarian logistics, such as donors, logistics providers, aid agencies, governments, non-governmental organizations, and the military (3).

Humanitarian logistics need for children: Children experience difficult situations in gaining access to aid. First, children physically are weaker than adults, and their ability in reaching humanitarian assistance is lower than others. It exacerbates especially when poorly managed humanitarian logistics is happening in the affected area. Poorly managed Humanitarian logistics do more harm to children than adults (4).

Another obstacle for children in gaining humanitarian aid is logistics equipment and vehicles. Most equipment, vehicles, cars, etc. are made for adult height and ability. For example, adults can gain aid easier from a truck than children. Another example is that it is harder when girls want to receive humanitarian aid. Wrong timing for distribution leads to the complexity of aid access for girls and children and people with special needs (5). There are studies that showed that during disasters, unfortunately, sexual assault happened by aid distributors toward minor girls. It happens because of the acute needs of girls for aid like food, medicine, and shelter (1).

Another important issue in the distribution of aid is the size of aid packages. Many aid packages are made for adults. There are various reasons for oversized packages: oversizing packages can happen from planning. When ordering packages from factories, during its packaging, should be considered that children are one of the consumers. Also, oversizing packages may have occurred in humanitarian organizations when their volunteers are packaging goods. A large and heavy package of for example food, water and cloth are unbearable for children, but 
they have no choice but to receive it. Distribution type of goods like throwing that to the crowd in poorly managed humanitarian logistics make this issue more complicated. Neglecting children in aid packaging may result in trauma, injuries, and fractures in children.

In humanitarian logistics, planning and implementing special needs of children are vital. Children of different ages from newborn to 18 years old have different needs for exceptional food, clothes, shelter, etc. Thus, special requirements for each age and gender group should be assessed during needs assessment for every context (5).

Logisticians in many disasters are not prepared for confronting with gender differences, and often children (5). Working with children needs special knowledge about their emotional, psychological, and physical aspects. Children have less coping than adults. Therefore, the same behavior with children and adults during humanitarian logistics may result in psychological trauma in children.

What is needed to improve humanitarian logistics for children in the future? Hearing the voice of children in humanitarian logistics is an important topic that should be considered (6). Article 12 of the United Nations Convention on the Rights of the Child (UNCRC) states that "State parties shall assure to the child who is capable of forming his or her own views the right to express those views freely in all matters affecting the child, the views of the child being given due weight in accordance with the age and maturity of the child." In accordance with article 2 of the convention, states should respect to all matters affecting children. This respect should be considered irrespective of diversity. Children's participation in planning and implementing humanitarian logistics can help this process for better services. For example, their idea about the type of aid, packaging, distribution timing and location, distribution vehicles, and many other aspects will be valuable.

Enhancing the knowledge of different actors in humanitarian logistics is very important and vital for children's health. Donors, producers, governments, humanitarian organizations, other non-governmental organizations, and the military should learn more about children's needs. They should consider children's interest from planning to implement their efforts in humanitarian logistics from the top (managers, etc.) to bottom (aid worker, driver, soldier, etc.) of their hierarchy and it will enormously affect children's health and wellbeing during and after disasters.

All stakeholders in natural disasters should consider children in their policies. Emphasizing on children in policies and attention to their needs for humanitarian logistics can be done at different levels like local, regional, national, and international. Some child humanitarian organizations like UNICEF and Save the children professionally work on children's needs in humanitarian logistics, but they work more on international missions. It is important that national governments and humanitarian organizations focus on child-friendly humanitarian logistics.

By reviewing the literature with different terms like children, girls, boys, humanitarian aid, logistics, the supply chain in different databases, it is hard to find studies that focus directly on children and humanitarian logistics in natural disasters.

Researchers have an essential role to be the voice of children in natural disasters. Studies on children's needs for humanitarian logistics and studying the effect of poorly managed humanitarian logistics on girls and boys, separately, are valuable for humanitarian logistics in practice. Attention to the relation of humanitarian logistics with some age-related development periods from infancy to adolescence will be informative too. Each disaster should be analyzed separately to decrease the adverse effects of humanitarian aid because the context, severity, and type of disasters are different. In order to address the context and disaster, the humanitarian logistics should be tailored to the needs of children while minimizing undesirable aspects of improper distribution of aid.

\section{Footnotes}

Conflict of Interests: The authors have no conflicts of interest to declare.

Financial Disclosure: It is not declared by the authors. Funding/Support: It is not declared by the authors.

\section{References}

1. Seddighi H, Salmani I, Javadi MH, Seddighi S. Child abuse in natural disasters and conflicts: A systematic review. Trauma Violence Abuse. 2019:1.524838019836E+15. doi: 10.1177/1524838019835973. [PubMed: 30866745]

2. Thomas V, Lopez R. Global increase in climate-related disasters - ADB economics working paper series, 466. 2015.

3. Kovacs G, Jahre M, Spens KM. Humanitarian logistics in disaster relief operations. Int J Phys Distrib Logist Manag. 2007;37(2):99-114. doi: 10.1108/09600030710734820.

4. Perrin P. The impact of humanitarian aid on conflict development. Int Rev Red Cross. 1998;38(323):319-33. doi: 10.1017/s0020860400091051.

5. Kovacs G, Tatham P. Humanitarian logistics performance in the light of gender. Int J Prod Perform Manag. 2009;58(2):174-87. doi: $10.1108 / 17410400910928752$.

6. Bouma H, Lopez Lopez M, Knorth EJ, Grietens H. Meaningful participation for children in the Dutch child protection system: A critical analysis of relevant provisions in policy documents. Child Abuse Negl. 2018;79:279-92. doi: 10.1016/j.chiabu.2018.02.016. [PubMed: 29499479]. 